\title{
On the acoustic diffraction by the edges of benthic shells
}

\author{
Timothy K. Stanton a) and Dezhang Chu \\ Department of Applied Ocean Physics and Engineering, Woods Hole Oceanographic Institution, \\ Woods Hole, Massachusetts 02543-1053
}

(Received 15 September 2003; revised 7 January 2004; accepted 14 January 2004)

\begin{abstract}
Recent laboratory measurements of acoustic backscattering by individual benthic shells have isolated the edge-diffracted echo from echoes due to the surface of the main body of the shell. The data indicate that the echo near broadside incidence is generally the strongest for all orientations and is due principally to the surface of the main body. At angles well away from broadside, the echo levels are lower and are due primarily to the diffraction from the edge of the shell. The decrease in echo levels from broadside incidence to well off broadside is shown to be reasonably consistent with the decrease in acoustic backscattering from normal incidence to well off normal incidence by a shell-covered seafloor. The results suggest the importance of the edge of the shell in off-normal-incidence backscattering by a shell-covered seafloor. Furthermore, when considering bistatic diffraction by edges, there are implications that the edge of the shell (lying on the seafloor) can cause significant scattering in many directions, including at subcritical angles. (C) 2004 Acoustical Society of America. [DOI: 10.1121/1.1675813]
\end{abstract}

PACS numbers: $43.30 . \mathrm{Sf}, 43.30 . \mathrm{Hw}$ [KGF]

Pages: $239-244$

\section{INTRODUCTION}

There is significant evidence that benthic shells, when occurring in sufficiently large numbers, can dominate acoustic backscattering by the seafloor, especially at angles of incidence away from normal (Jackson et al., 1986; Stanic et al., 1989; Fenstermacher et al., 2001; Stanton, 2000; Williams et al., 2001). A major limiting factor in the analyses of these data has been the lack of understanding of the fundamental scattering process of the shells. The shape of the shells is complex and it is impossible to formulate exact analytical models. Stanton et al. (2000) have recently shown that the scattering by one class of benthic shells, periwinkles, whose shape is rounded (low aspect ratio), has significant contributions from the front interface, the interface exposed from the opercular opening for certain orientations, and Lamb circumferential waves for other orientations.

In this paper, measurements of the backscattering by empty bivalve and sand dollar shells in free space (i.e., away from boundaries) are presented. In contrast to the periwinkles studied in Stanton et al. (2000), these shells have an oblate shape (high aspect ratio) with distinct edges around the perimeter of the bodies. Applying a pulse-compression technique to the broadband echoes, the diffraction by the edges are resolved over a wide range of orientation angles. The results are compared with the scattering by a machined aluminum disk of similar dimensions, which provides additional insight into the scattering process. The results are also compared with previously published scattering measurements from two cases involving a shell-covered seafloor. The significance of the edge in the scattering process is discussed both with respect to backscattering by a shell-covered seafloor and penetration of acoustic energy into the seafloor.

a)Electronic mail: tstanton@whoi.edu

\section{EXPERIMENT}

The experiment involved insonifying individual bivalve shells (one-half shell at a time), sand dollar shells, and machined circular metal disks with a broadband acoustic signal in a laboratory tank. The shells were empty. Both backscattering and forward scattering were measured. Since the analysis below involves just backscattering from one scatterer per category listed above, experimental data presented cover only relavent information.

\section{A. Targets}

The bivalve was collected off of Florida as part of the SAX99 experiment (Thorsos et al., 2001) and the sand dollar was collected near Humboldt Bay, CA. The disk was machined out of aluminum, which has a similar density and sound speed as that of the shells. All objects were of comparable size (Table I) so that comparisons of the scattering characteristics could be made (Fig. 1). The three objects represent, in essence, a progression of shapes of increasing complexity. The machined disk, used as a control target, is flat and circular. The sand dollar is generally circular, mostly flat on one side, and rounded on the other side. The one-half bivalve shell has an edge in a somewhat elliptical pattern with an open surface that is concave. The surface and edge of the sand dollar are generally smooth while these features of the bivalve are corrugated.

\section{B. Experimental setup}

The acoustic scattering measurements were conducted in a flume tank filled with fresh water in Fall 2002 (Fig. 2). The tank was $23 \mathrm{~m}$ long, with a square cross section $1.2 \mathrm{~m}$ on a side. The targets and acoustic transducers were placed in the center of the cross section of the tank. A pair of closely spaced transducers was used, one as transmitter and the other as receiver, to emit and receive a broadband chirp (linear frequency modulated) signal over the frequency range 40-95 
TABLE I. Dimensions of targets. The terms "horizontal" and "vertical" refer to cross dimensions of the objects in the deployed position (Fig. 2), thus the vertical dimension is measured along a line parallel to the tethers shown in Fig. 1 and the horizontal dimension is along a perpendicular line. The upper camber gives an indication of the curvature of the shells. With the flat side of the sand dollar or concave side of the bivalve on a flat surface, the upper camber is the largest distance or deviation measured between the surface and the opposite side of the shell. Since the disk is flat, this measurement corresponds to its thickness of $0.19 \mathrm{~cm}$. The aluminum is an alloy (\#6061), received a T6 heat treatment, and contained $97.92 \%$ aluminum.

\begin{tabular}{|c|c|c|c|c|c|}
\hline Target & $\begin{array}{c}\text { Species or } \\
\text { material }\end{array}$ & ID no & $\begin{array}{l}\text { Horizontal } \\
\text { dimension } \\
(\mathrm{cm})\end{array}$ & $\begin{array}{c}\text { Vertical } \\
\text { dimension } \\
(\mathrm{cm})\end{array}$ & $\begin{array}{l}\text { Upper camber } \\
(\mathrm{cm})\end{array}$ \\
\hline disk & Aluminum & AL02-4 & 8.0 & 8.0 & 0.19 \\
\hline sand dollar & $\begin{array}{l}\text { Dendraster } \\
\text { excentricus }\end{array}$ & HSU02-02 & 7.25 & 6.7 & 1.1 \\
\hline bivalve & $\begin{array}{l}\text { Dinocardium } \\
\text { robustum } \\
\text { vanhyningi }\end{array}$ & SAX99-C-08 & 7.0 & 6.9 & 2.9 \\
\hline
\end{tabular}

kHz. The received signal was digitized with a digital oscilloscope and stored onto a personal computer for postprocessing. The target was rotated with a computer-controlled stepper motor in $1^{\circ}$ increments between pings, so that scattering could be measured over a $360^{\circ}$ range of orientations. Care was taken so that multi-path echoes from all surfaces of the narrow tank did not interfere with the echoes of interest. Once the echoes were temporally compressed through cross correlating the echoes with the calibration signal, the multipath signals were resolved and eliminated in the analysis. Because of the finite dimensions of the transducers, the twotransducer setup deviated from true backscatter. The centerto-center separation between the transducers was $0.33 \mathrm{~m}$ and the target-transducer separation was $3.0 \mathrm{~m}$, resulting in a $6.3^{\circ}$ deviation from true backscatter. Details of the pulse compression signal processing, electronics, measurement procedure, and calibration are given in Chu and Stanton (1998), Stanton et al. $(1998,2000)$, and Reeder et al. (in press).

\section{RESULTS}

The backscattering by all three objects was strongly directional (Figs. 3-6). This dependence is consistent with the fact that $k D \gg 1$, where $k(=2 \pi / \lambda$, where $\lambda$ is the acoustic wavelength) is the acoustic wavenumber and $D$ is a characteristic outer dimension, such as length, width, or diameter. The scattering is shown to be strongest near broadside incidence with the exception of the convex aspect of the bivalve. The scattering pattern is especially strong and directional near broadside incidence for the flat surfaces since, in these cases, the echoes from a flat interface tend to add constructively and dominate the scattering.

Well away from broadside, diffraction from edges becomes important. This is best illustrated through use of the temporally compressed signal (Figs. 4-6). In the color contour plots of scattered pressure versus orientation, the edge diffracted waves produce a nearly sinusoidal pattern, which is especially apparent in the data concerning the disk and, to some extent from the sand dollar. The patterns from the machined metallic disk and sand dollar show multiple orders of diffraction, due to multiple circumnavigations around the surfaces of the targets. The first-order return is from a direct arrival from the leading or trailing edge. The second-order return is from diffraction by one edge (leading or trailing), traveling along the surface of the target, then diffraction by the other edge. (Similarly, higher order returns appear at times corresponding to higher-order circumnavigations.

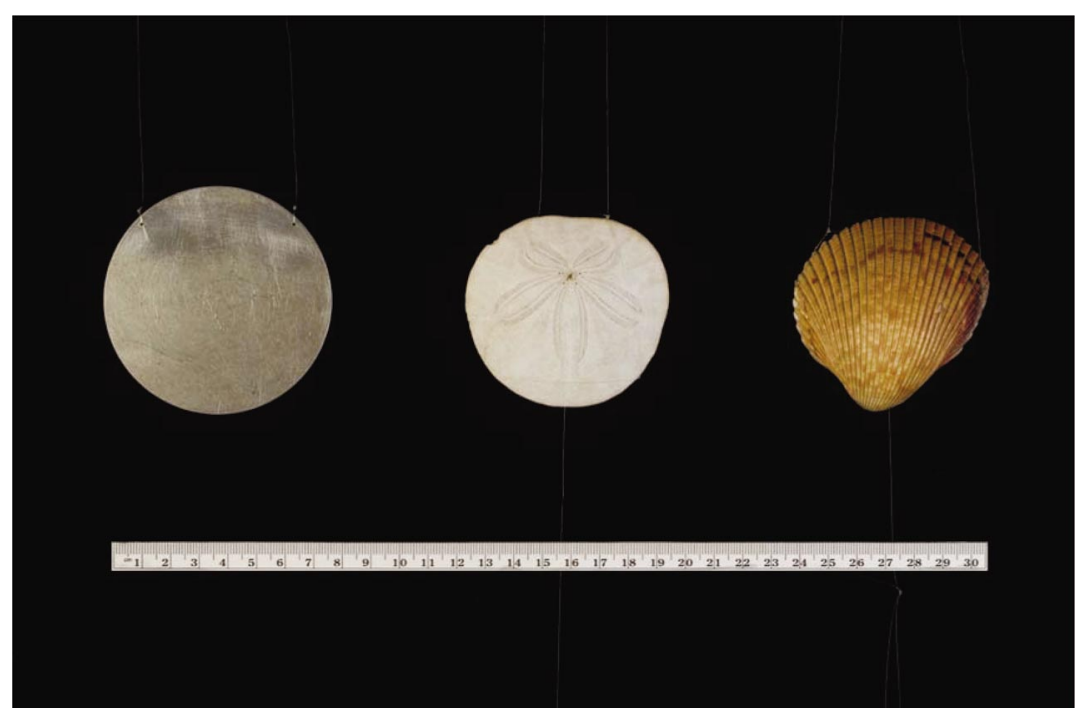

FIG. 1. Photo of targets used in acoustic scattering measurements. Left: aluminum disk, middle: sand dollar, and right: bivalve. Centimeter ruler in photo for scale. The thin lines perpendicular to the ruler are the tethers used to suspend and rotate the targets. 


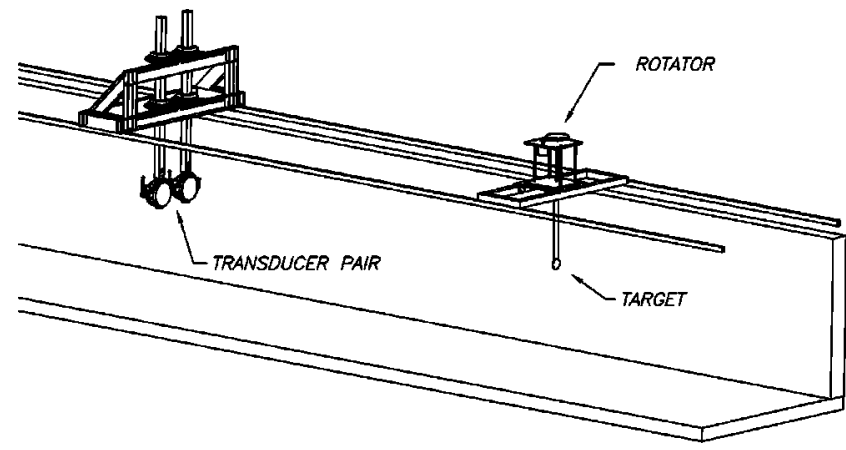

FIG. 2. Sketch of backscattering measurement. Thickness of tethers exaggerated for purpose of illustration.

Travel times along the surface are associated with waves of supersonic speeds, at least for the disk.

There is a striking resemblance between the pattern of first-order edge-diffracted waves from the sanddollar and metallic disk. In addition to the similar near-sinusoidal patterns, both show consistent strength across much of the range of orientation away from broadside incidence. There are important differences between the patterns as well-for example, near broadside, the main lobe of the scatter pattern of the sand dollar is asymetrical about the plane of the body since one side is nearly flat and the other side is rounded.

The scatter pattern from the bivalve is more complex than those of the other targets. Since the radius of curvature of the shell is smaller than that of the other targets and the shell subtends such a large range of angles, the main lobe of the scatter pattern is much broader than those of the other targets. In fact, most of the pattern is from either the scattering from the convex surface (e.g., $110^{\circ}$ to $250^{\circ}$ ) or concave surface $\left[\right.$ e.g., $-70^{\circ}\left(290^{\circ}\right)$ to $50^{\circ}$ ]. Over a small span of orientations (e.g., $50^{\circ}$ to $110^{\circ}$ and $250^{\circ}$ to $290^{\circ}$ ) where the surface scattering is not dominating, there are features that correspond to edge diffraction.

The physics of the scattering by these elastic objects is complex and a detailed description of the various scattering mechanisms associated with the scattering is beyond the scope of this work. The reader is referred to the experimental studies of the scattering by elastic disks presented in Hefner (2000) and Hefner and Marston (2001, 2002). In those studies, the pattern of scattering by the edges was observed. Also, other effects, involving excitation of Lamb waves, were observed and described in those studies. The series of echoes near $20^{\circ}$ and $160^{\circ}$ in Figs. 4 and 5 of this work are consistent with such excitation. For analytical and numerical descriptions of scattering by impenetrable curved or bounded edges, as well as more experimental results, the reader is referred to the works of Lyamshev (1999), Kristensson and Waterman (1982), Norton et al. (1993), Medwin (1981), Jebsen and Medwin (1982), and Svensson et al. (1999).

\section{IMPLICATIONS FOR SCATTERING BY SHELL-COVERED SEAFLOOR}

Because of the significant observed diffraction by the edge of the shells, there are implications of the importance of the diffraction by the edge of the shells both in applications of backscattering as well as penetration of the acoustic energy into the seafloor.

\section{A. Backscattering}

The results show that the diffraction by the edge in the backscattering direction for oblique orientations is generally about 10-30 dB below the level of the backscattering from the shell for near-broadside orientations where the shell surface dominates the scattering. In order to understand the importance of this level in the context of acoustic scattering by a shell-covered seafloor, data from the seafloor are required. There are limited scientific data available to date for this particular type of scattering.

In one study involving the bivalve used in this analysis, a number of known shells were laid on the seafloor and the backscattering was measured at $40 \mathrm{kHz}$ and at a fixed grazing angle of $16^{\circ}$. This experiment, known by the name SAX99, was conducted in the Gulf of Mexico in 1999 and is described, in part, in Thorsos et al. (2001) and Williams et al. (2001). The bivalve used in the measurements described herein was 1 of the 81 large shells (all approximately $6 \mathrm{~cm}$ in diameter) used in the SAX99 experiment. In one of the (SAX99) measurements involving just the large shells, the bivalves were laid out on the seafloor in a random spacing with a number density of about $20 / \mathrm{m}^{2}$, all with the concave side in the upward direction. The measured area scattering strength (or, equivalently, target strength of a square meter of seafloor) as defined in Urick (1983) was - $27 \mathrm{~dB}$. The target strength of the bivalve in this study at an orientation of $74^{\circ}$ (concave aspect, Fig. 3), which corresponds to the $16^{\circ}$ grazing angle, is about $-42.5 \mathrm{~dB}$. Although this value corresponds to the $70-\mathrm{kHz}$ frequency component, a
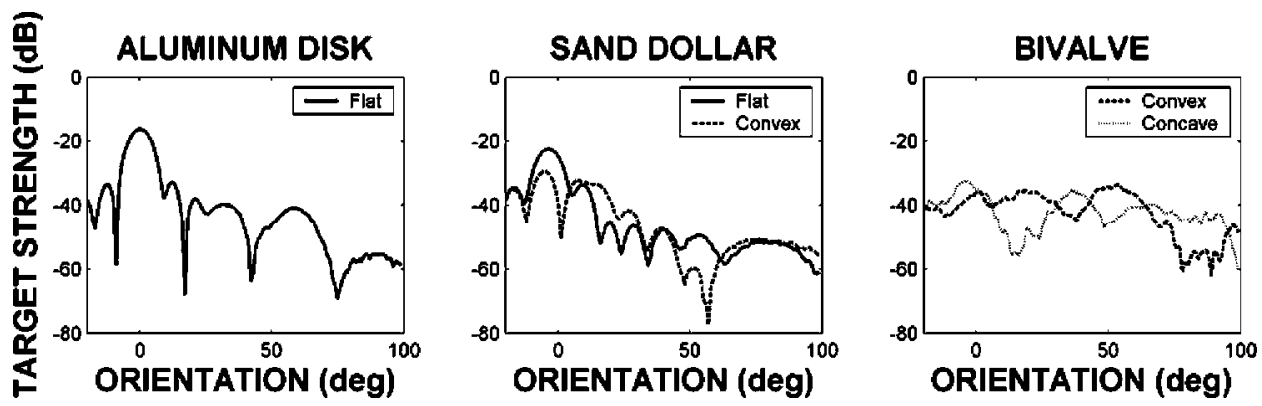

FIG. 3. Target strength derived from $70-\mathrm{kHz}$ component of echo versus orientation for each target. Since the spectral component of the signal is inherently narrow-band, various scattering highlights are not temporally resolved in this plot. The orientation is relative to broadside incidence $\left(0^{\circ}\right)$ for each surface of each target, thus the angles in this plot may not directly correspond with the angles given in Figs. $4-6$ where broadside occurs at $0^{\circ}$, $180^{\circ}$, and $360^{\circ}$. 


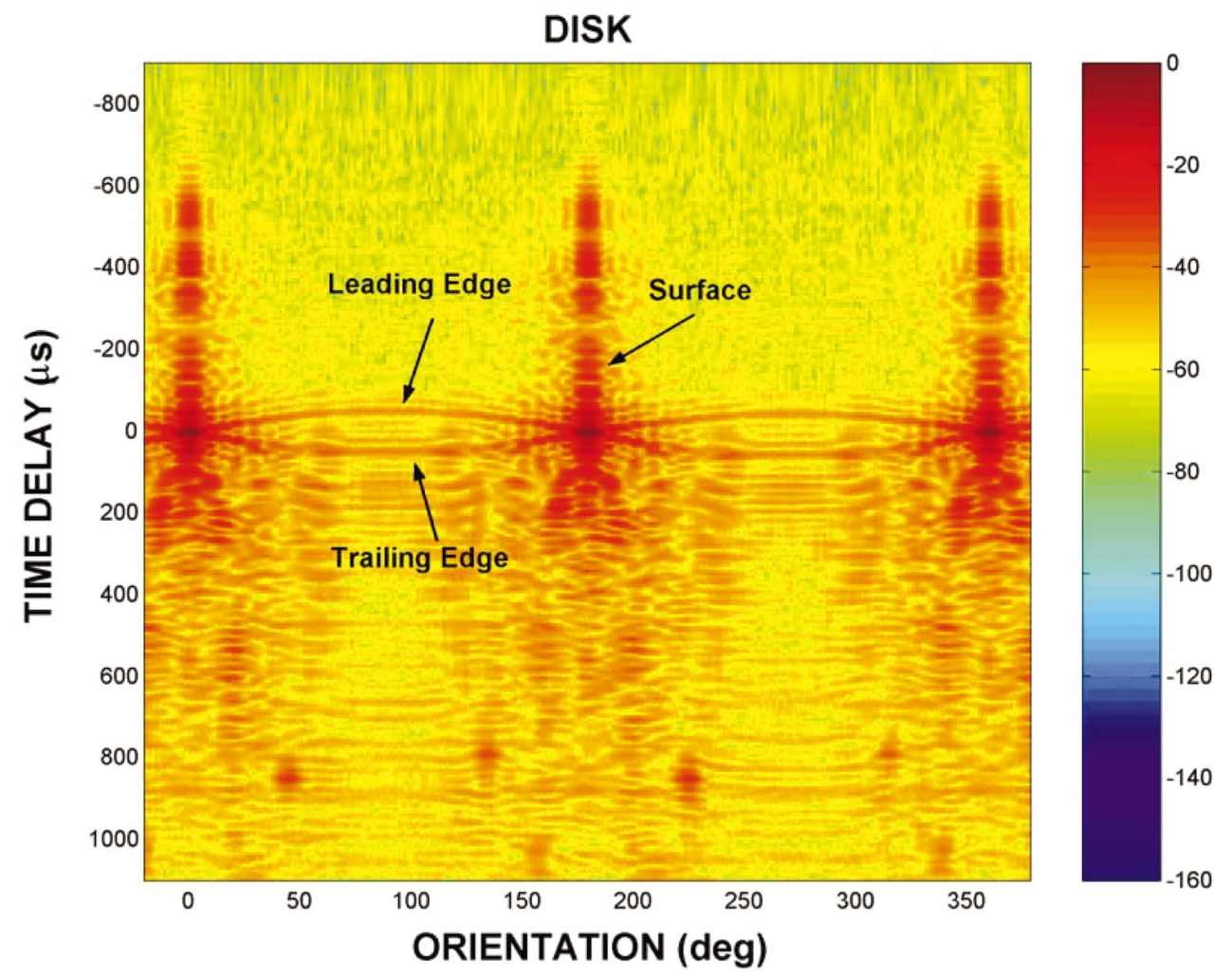

FIG. 4. Color contour image of temporally compressed echo versus orientation for aluminum disk. Various echoes from the target are resolved, including diffracted echoes from leading and trailing edges of the target and echo from surface. Range resolution of this signal is approximately $2 \mathrm{~cm}$. The color scale is in $\mathrm{dB}$ relative to the maximum value. Apparent echoes from the surface at orientations near $0^{\circ}, 180^{\circ}$, and $360^{\circ}$ arriving at negative time delays are actually processing sidelobes from the large 0 -time-delay echoes.

similar range of values was observed at $50 \mathrm{kHz}$ (not shown) and presumably it would be similar at $40 \mathrm{kHz}$ as well (the 40 $\mathrm{kHz}$ component is at the edge of the band and is not included in this analysis). Using Eqs. (2) and (4) from Stanton (2000), the area scattering strength (same definition as above) from an aggregation of randomly distributed targets lying on a planar low-reflective substrate is approximately $S_{A}=T S$ $+10 \log n$, where $n$ is the numerical density. From this equa-

\section{SAND DOLLAR}

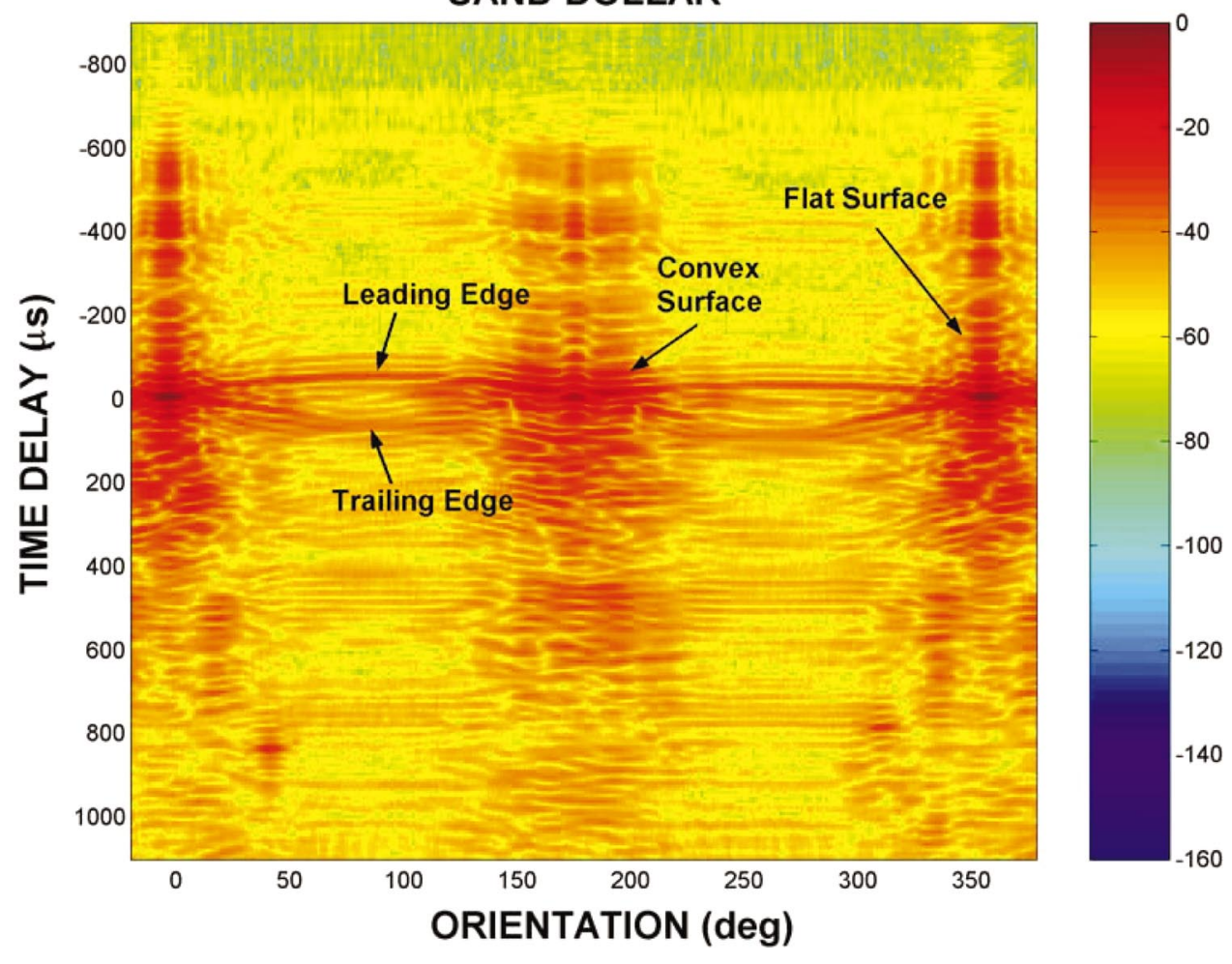

FIG. 5. Color contour image of temporally compressed echo versus orientation for the sand dollar. See caption to Fig. 4 for more details. 


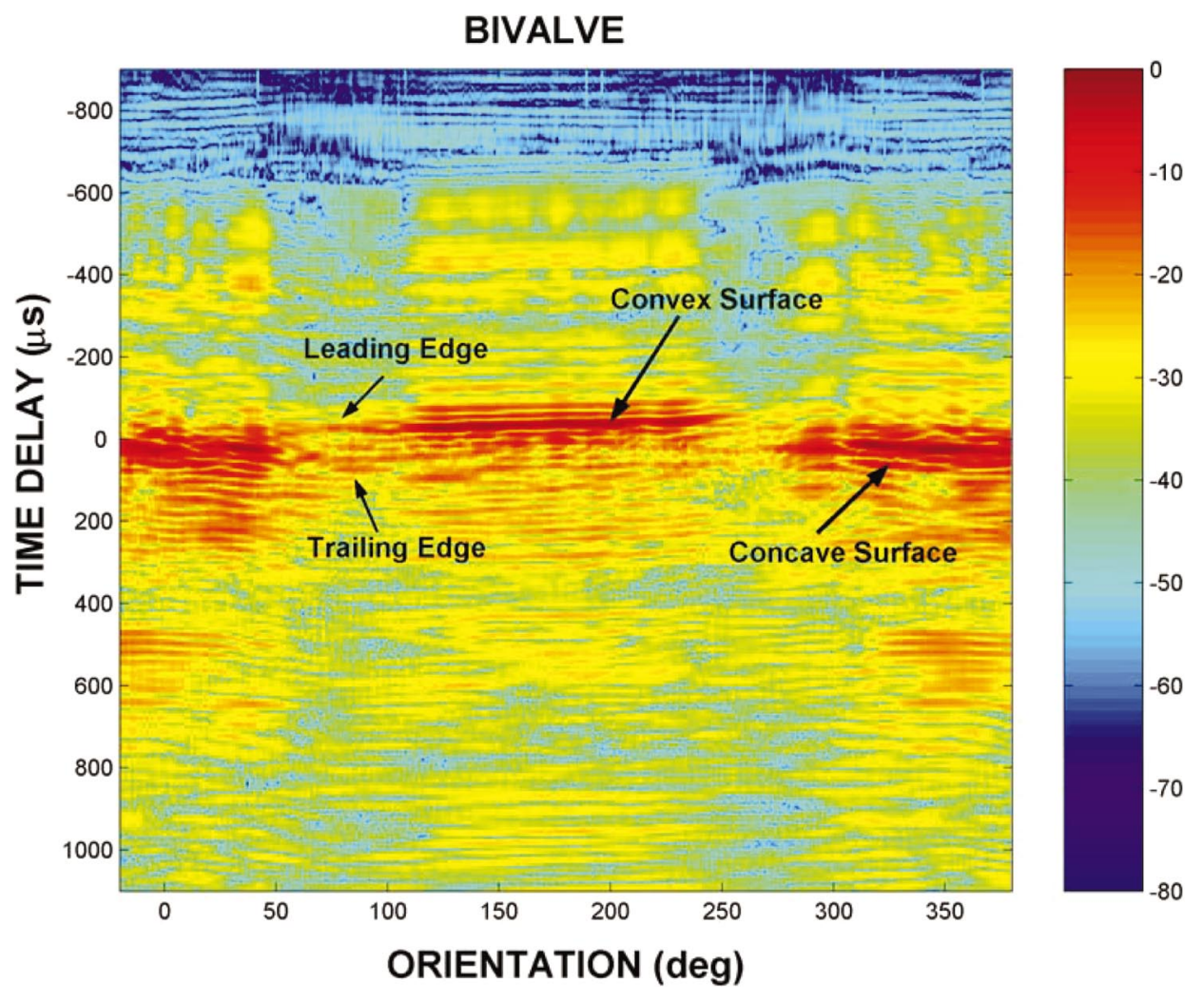

FIG. 6. Color contour image of temporally compressed echo versus orientation for bivalve. See caption to Fig. 4 for more details.

tion, and assuming all targets have the same target strength of $-42.5 \mathrm{~dB}$, the area scattering strength is predicted at approximately $-29.5 \mathrm{~dB}$. This predicted value is about $2.5 \mathrm{~dB}$ lower than the observed value in the SAX99 experiments. Of course, the model had approximations, and, very importantly, the target-to-target variability and effects due to the seafloor substrate (such as its roughness and the edge-seafloor ray path) were not taken into account. For example, the scattering strength by the seafloor without the shells was $-31 \mathrm{~dB}$. Assuming that the echoes from the shells and seafloor add incoherently and that the shells shadowed only a small fraction of the seafloor, then the combination of scattering by the seafloor and shells would be approximately $27.2 \mathrm{~dB}$, which is essentially the same as the observed value of the shellcovered seafloor. Accounting for the shell-seafloor ray path can further enhance the contribution from the shells-an effect predicted by Williams et al. (2001) in the case of marbles. Although these are crude estimates, the backscattering value of the individual shell provides a plausible explanation for the increase in scattering by the seafloor when shells are present. As shown in Fig. 6, this region of shallow grazing angles $\left(16^{\circ}\right)$ corresponds to the angles (near $74^{\circ}$ ) at which the edge of the shell is contributing significantly to the scattering. Thus, it is important to account for the edge of the shell when making scattering predictions at angles well off normal incidence.

In another study, Jackson et al. (1986) presented results of measurements of backscattering as a function of grazing angle for a shell-covered seafloor over the range $20-50 \mathrm{kHz}$. The seafloor was nearly completely covered with a thick, dense layer of live mussels and cockles (both types are bivalves) (Darrell Jackson, personal communication, 1998). The grazing angles ranged from $90^{\circ}$ (normal incidence) down to about $10^{\circ}$. The data show that the backscattering by a shell-covered seafloor at angles well away from normal incidence is about $20 \mathrm{~dB}$ below the levels at normal incidence. This amount of decrease is essentially the same as for the convex case of the bivalve at the corresponding orientation of $80^{\circ}$ in Fig. 3 and $100^{\circ}$ in Fig. 6 (only the convex side of the live mussels and cockles are "seen" by the acoustic system). The comparison is not definitive since the shells in the Jackson et al. (1986) paper were not documented. Also, it is conceivable that the shells in their study were oriented such that there were significant contributions to the scattering from the surface of the shells. Nonetheless, since the edge-diffracted echoes are significant at these angles, the comparison shows that it is possible that the diffraction by the edges alone could dominate the backscattered echo at angles well off normal incidence.

\section{B. Bottom penetration}

The demonstration of the importance of the edge diffracted wave in the backscatter direction also has significance for the bistatic geometry. It has been demonstrated both theoretically and experimentally that edges can diffract an acoustic wave into directions other than the forward direction. For example, in the work of Bremhorst (1978) and Medwin (1981), it is shown that the diffracted wave due to a semi-infinite plate is in the range -15 to $-25 \mathrm{~dB}$ below the level of the incidence wave for the case where the source is near the plate and for diffraction angles $90^{\circ}$ past the forward diffraction angle [i.e., curve $\theta=270^{\circ}$ of Fig. 5 in Medwin (1981)]. For the seafloor problem, this angle would correspond to a shallow grazing incidence angle and near-vertical penetration of the diffracted wave. Although the edges of that 
study were straight and impenetrable, it is reasonable to expect a similar effect for the curved and penetrable edges of the benthic shell, even when lying on a penetrable surface such as the seafloor.

If the edges of the shell diffract energy into directions different than that of the incident field, then a shell lying on the seafloor will diffract sound into the seafloor, which is also penetrable acoustically. A bed of randomly located, randomly oriented shells can scatter sound diffusely into the seafloor. It is known that for grazing angles below a certain value (i.e., the critical angle), sound will not penetrate a flat homogeneous seafloor. However, the presence of shells with edges can cause the sound to scatter into the seafloor at these angles due to diffraction by the edges. Because of this effect, objects within the seafloor could possibly be detected acoustically at subcritical angles when shells are present that could not have otherwise been detected.

\section{SUMMARY AND CONCLUSIONS}

Measurements have been made in which the free-field acoustic diffraction by the edge of individual benthic shells has been isolated from echoes from the shell surface. The diffracted echoes are shown to be of a strong enough level to be potentially significant in applications of acoustic scattering by a shell-covered seafloor. For backscattering applications, the ratio of the (free-field) edge-diffracted echo at oblique angles of incidence to the surface-scattered echo at broadside incidence is shown in one case to be comparable to the corresponding ratio (involving shallow grazing angles and normal incidence) for a shell-covered seafloor. These results imply that there may be conditions under which the edge of the shells can dominate the backscattering by a shellcovered seafloor for angles off of normal incidence. Another implication from these results is that the edge may cause significant penetration of acoustic energy into the seafloor, even at angles below the critical angle. This has importance in detecting targets that are below the water/bottom interface.

Although the results of this study are strongly suggestive in the applications to a shell-covered seafloor, verification is required such as through experimentation and simulation. Very importantly, the influence of the water/bottom interface on the edge-diffracted echo needs to be explored.

\section{ACKNOWLEDGMENTS}

This research was supported by the U.S. Office of Naval Research (Grant No. N00014-02-1-0095) and the Woods Hole Oceanographic Institution (WHOI), Woods Hole, MA. The authors are grateful to Craig Johnson of WHOI for constructing the mechanical mounts for the measurements, Shirley Barkley (WHOI) for preparing the manuscript to this paper, and Tom Kleindinst (WHOI) for taking the photograph for Fig. 1.
Bremhorst, J. H. (1978). "Impulse wave diffraction by wedges and plates," M.S. thesis, Naval Postgraduate School, December.

Chu, D., and Stanton, T. K. (1998). "Application of pulse compression techniques to broadband acoustic scattering by live individual zooplankton," J. Acoust. Soc. Am. 104, 39-55.

Fenstermacher, L. E., Crawford, G. B., Borgeld, J. C., Britt, T., George, D. A., Klein, M. A., Driscoll, N. W., and Mayer, L. A. (2001). "Enhanced acoustic reflectivity due to high abundance of sand dollars, Dendraster excentricus," Marine Georesources Geotechnol. 19, 135-145.

Hefner, B. T. (2000). "Acoustic backscattering enhancements for circular elastic plates and acrylic targets, the application of acoustic holography to the study of scattering from planar elastic objects, and other research on the radiation of sound," $\mathrm{Ph} . \mathrm{D}$. thesis, Washington State University.

Hefner, B. T., and Marston, P. L. (2001). "Backscattering enhancements associated with the excitation of symmetric Lamb waves on a circular plate: direct and holographic observations," ARLO 2, 55-60.

Hefner, B. T., and Marston, P. L. (2002). "Backscattering enhancements associated with antisymmetric Lamb waves confined to the edge of a circular plate: direct and holographic observations," ARLO 3, 101-106.

Jackson, D. R., Baird, A. M., Crisp, J. J., and Thompson, P. A. G. (1986). "High-frequency bottom backscatter measurements in shallow water," J. Acoust. Soc. Am. 80, 1188-1199.

Jebsen, G. M., and Medwin, H. (1982). "On the failure of the Kirchhoff assumption in backscatter," J. Acoust. Soc. Am. 72, 1607-1611.

Kristensson, G., and Waterman, P. C. (1982). "The $T$ matrix for acoustic and electromagnetic scattering by circular disks," J. Acoust. Soc. Am. 72, 1612-1625.

Lyamshev, L. M. (1999). "Nonspecular reflection, resonance scattering and radiation of sound by plates and shells in water," Acoust. Phys. 45, 693716.

Medwin, H. (1981). "Shadowing by finite noise barriers," J. Acoust. Soc. Am. 69, 1060-1064.

Norton, G. V., Novarini, J. C., and Keiffer, R. S. (1993). "An evaluation of the Kirchhoff approximation in predicting the axial impulse response of hard and soft disks," J. Acoust. Soc. Am. 93, 3049-3056.

Reeder, D. B., Jech, J. M., and Stanton, T. K. (in press). "Broadband acoustic backscatter and high-resolution morphology of fish: Measurement and modeling," J. Acoust. Soc. Am.

Stanic, S., Briggs, K. B., Fleischer, P., Sawyer, W. B., and Ray, R. I. (1989). "High-frequency acoustic backscattering from a coarse shell ocean bottom," J. Acoust. Soc. Am. 85, 125-136.

Stanton, T. K. (2000). "On acoustic scattering by a shell-covered seafloor," J. Acoust. Soc. Am. 108, 551-555.

Stanton, T. K., Chu, D., Wiebe, P. H., Martin, L., and Eastwood, R. L. (1998). "Sound scattering by several zooplankton groups. I. Experimental determination of dominant scattering mechanisms," J. Acoust. Soc. Am. 103, 225-235.

Stanton, T. K., Chu, D., Wiebe, P. H., Eastwood, R. L., and Warren, J. D. (2000). "Acoustic scattering by benthic and planktonic shelled animals," J. Acoust. Soc. Am. 108, 535-550.

Svensson, U. P., Fred, R. I., and Vanderkooy, J. (1999). "An analytic secondary source model of edge diffraction impulse responses," J. Acoust. Soc. Am. 106, 2331-2344.

Thorsos, E. I., Williams, K. L., Chotiros, N. P., Christoff, J. T., Commander, K. W., Greenlaw, C. F., Holliday, D. V., Jackson, D. R., Lopes, J. L., McGehee, D. E., Piper, J. E., Richardson, M. D., and Tang, D. (2001). "An overview of SAX99: Acoustic measurements," IEEE J. Ocean. Eng. 26, 4-25.

Urick, R. J. (1983). Principles of Underwater Sound (McGraw-Hill, New York).

Williams, K. L., Richardson, M. D., Briggs, K. B., and Jackson, D. R. (2001). "Scattering of high-frequency energy from discrete scatterers on the seafloor: Glass spheres and shells," Proc. Inst. Acoust. 23, 369-374. 